Special Article

\title{
Medication Management in Frail Older People: Consensus Principles for Clinical Practice, Research, and Education
}

\author{
Shin J. Liau BPharm (Hons) ${ }^{\mathrm{a}, \mathrm{b}}$, Samanta Lalic $\mathrm{PhD}^{\mathrm{a}} \mathrm{c}$, Janet K. Sluggett $\mathrm{PhD}^{\mathrm{a}} \mathrm{d, \textrm {e }}$, \\ Matteo Cesari MD, $\mathrm{PhD}^{\mathrm{f}}$, Graziano Onder MD, $\mathrm{PhD}^{\mathrm{g}}$, Davide L. Vetrano MD, PhD ${ }^{\mathrm{h}, \mathrm{i}}$, \\ Lucas Morin $\mathrm{PhD}^{\mathrm{j}, \mathrm{k}}$, Sirpa Hartikainen $\mathrm{MD}, \mathrm{PhD}^{1}$, Aleksi Hamina $\mathrm{PhD}^{1, \mathrm{~m}}$, \\ Kristina Johnell $\mathrm{PhD}^{\mathrm{n}}$, Edwin C.K. Tan $\mathrm{PhD}^{\circ}$, Renuka Visvanathan $\mathrm{PhD}^{\mathrm{b}}{ }^{\mathrm{b}} \mathrm{p}$, \\ J. Simon Bell PhD ${ }^{\mathrm{a}, \mathrm{b}, \mathrm{l}, *}$, on behalf of the Optimizing Geriatric Pharmacotherapy through \\ Pharmacoepidemiology Network (OPPEN)
}

${ }^{a}$ Centre for Medicine Use and Safety, Faculty of Pharmacy and Pharmaceutical Sciences, Monash University, Melbourne, Australia

${ }^{\mathrm{b}}$ National Health and Medical Research Council (NHMRC) Centre of Research Excellence in Frailty and Healthy Ageing, Adelaide, Australia

${ }^{\mathrm{c}}$ Pharmacy Department, Monash Health, Melbourne, Australia

d School of Health Sciences, Division of Health Sciences, University of South Australia, Adelaide, Australia

e NHMRC Cognitive Decline Partnership Centre, Hornsby Ku-ring-gai Hospital, Hornsby, New South Wales, Australia

${ }^{\mathrm{f}}$ Fondazione IRCCS Ca' Granda Ospedale Maggiore Policlinico, University of Milan, Milan, Italy

${ }^{\mathrm{g}}$ Department of Cardiovascular, Endocrine-Metabolic Diseases and Aging, Istituto Superiore di Sanità, Rome, Italy

${ }^{\mathrm{h}}$ Aging Research Center, Department of Neurobiology, Care Sciences and Society, Karolinska Institutet and Stockholm University, Stockholm, Sweden

${ }^{\mathrm{i}}$ Centro Medicina dell'Invecchiamento, IRCCS Fondazione Policlinico Universitario A. Gemelli, and Università Cattolica del Sacro Cuore, Rome, Italy

${ }^{\mathrm{j}}$ Department of Medical Epidemiology and Biostatistics, Karolinska Institutet, Stockholm, Sweden

${ }^{\mathrm{k}}$ Inserm CIC 1431, University Hospital of Besançon, Besançon, France

${ }^{1}$ Kuopio Research Centre of Geriatric Care, School of Pharmacy, Faculty of Health Sciences, University of Eastern Finland, Kuopio, Finland

${ }^{\mathrm{m}}$ Norwegian Centre for Addiction Research (SERAF), Institute of Clinical Medicine, University of Oslo, Oslo, Norway

${ }^{\mathrm{n}}$ Department of Medical Epidemiology and Biostatistics, Karolinska Institutet, Stockholm, Sweden

${ }^{\circ}$ The University of Sydney School of Pharmacy, Faculty of Medicine and Health, Sydney, Australia

${ }^{\mathrm{p}}$ Adelaide Geriatrics Training and Research with Aged Care (GTRAC) Centre, Adelaide Medical School, Faculty of Health and Medical Sciences, University of Adelaide, Adelaide, Australia

\section{Keywords:}

Frailty

medication therapy management

aged

inappropriate prescribing

polypharmacy

multimorbidity

\begin{abstract}
A B S T R A C T
Frailty is a geriatric condition associated with increased vulnerability to adverse drug events and medication-related harm. Existing clinical practice guidelines rarely provide medication management recommendations specific to frail older people. This report presents international consensus principles, generated by the Optimizing Geriatric Pharmacotherapy through Pharmacoepidemiology Network, related to medication management in frail older people. This consensus comprises 7 principles for clinical practice, 6 principles for research, and 4 principles for education. Principles for clinical practice include (1) perform medication reconciliation and maintain an up-to-date medication list; (2) assess and plan based on individual's capacity to self-manage medications; (3) ensure appropriate prescribing and
\end{abstract}

The consensus principles have been endorsed by the International Conference on Frailty and Sarcopenia Research (ICFSR), the European Geriatric Medicine Society (EuGMS), and the Australian and New Zealand Society for Sarcopenia and Frailty Research (ANZSSFR).

SJL was supported by a postgraduate research scholarship funded by the Faculty of Pharmacy and Pharmaceutical Sciences, Monash University, and the Australian Government Research Training Program Scholarship. SJL and RV were supported by the National Health and Medical Research Council (NHMRC) Centre of Research Excellence in Frailty and Healthy Ageing. JKS was supported by a NHMRC Early Career Fellowship. AH was supported by a grant from the Pro Humanitate Foundation. ECKT was supported by NHMRC-ARC Dementia Research Development Fellowship. JSB was supported by a NHMRC Boosting Dementia Research Leadership Fellowship.

MC received honorarium from Nestlé for presentations at scientific meetings and held membership on the scientific advisory board. MC also received honorarium from Nutricia for presentations at scientific meetings. SH received a lecture fee from Astellas. RV was on the Clinical Governance Committee of Resthaven Inc. RV undertook consultancy for Nestlé. RV also received honoraria, travel, and accommodation support from Nestlé, Abbott and Nutricia over the past 3 years. JSB received grant income paid to his employer from NHMRC, Australian Government Department of Health, Victorian Government Department of Health and Human Services, Dementia Australia Research Foundation, GlaxoSmithKline and several aged care provider organizations. There are no other conflicts of interest to declare.

* Address correspondence to J. Simon Bell, PhD, Centre for Medicine Use and Safety, Faculty of Pharmacy and Pharmaceutical Sciences, Monash University, 407 Royal Parade, Parkville, Victoria 3052, Australia.

E-mail address: Simon.Bell2@monash.edu (J.S. Bell). 
deprescribing; (4) simplify medication regimens when appropriate to reduce unnecessary burden; (5) be alert to the contribution of medications to geriatric syndromes; (6) regularly review medication regimens to align with changing goals of care; and (7) facilitate multidisciplinary communication among patients, caregivers, and healthcare teams. Principles for research include (1) include frail older people in randomized controlled trials; (2) consider frailty status as an effect modifier; (3) ensure collection and reporting of outcome measures important in frailty; (4) assess impact of frailty on pharmacokinetics and pharmacodynamics; (5) encourage frailty research in under-researched settings; and (6) utilize routinely collected linked health data. Principles for education include (1) provide undergraduate and postgraduate education on frailty; (2) minimize low-value care related to medication management; (3) improve health and medication literacy; and (4) incorporate evidence in relation to frailty into clinical practice guidelines. These principles for clinical practice, research and education highlight different considerations for optimizing medication management in frail older people. These principles can be used in conjunction with existing best practice guidelines to help achieve optimal health outcomes for this vulnerable population. Implementation of the principles will require multidisciplinary collaboration between healthcare professionals, researchers, educators, organizational leaders, and policymakers.

(c) 2020 AMDA - The Society for Post-Acute and Long-Term Care Medicine.

The global number of older people is growing rapidly with a projection of 2 billion people aged over 60 years by 2050. ${ }^{1}$ Population aging has been accompanied by a concomitant rise in the number of older people living with multiple chronic conditions and frailty. ${ }^{2}$ Among people older than 85 years, it is estimated that $25 \%$ to $50 \%$ are frail. ${ }^{3}$ Frailty is a progressive yet potentially reversible decline in physiological reserve leading to a loss of dynamic homeostasis. ${ }^{4}$ It is characterized by increased vulnerability to adverse events and an impaired ability to cope with seemingly innocuous stressors.,

Recognition of frailty is a prerequisite for consideration of frailty in the treatment decision-making process. ${ }^{5}$ There is currently no internationally accepted reference standard to identify frailty. ${ }^{6}$ The Fried phenotype ${ }^{7}$ and the Rockwood Frailty Index ${ }^{8}$ remain common diagnostic tools. The European ADVANTAGE Joint Action partners also support opportunistic frailty screening of people aged 70 years and older in all healthcare settings using a screening tool that is quick to administer, validated, and does not require specialist equipment. ${ }^{9}$

Frailty is associated with shorter survival, poor quality of life, hospitalization, and admission to long-term care. ${ }^{4}$ There is emerging evidence to suggest an association between polypharmacy and incident prefrailty, although a causal relationship has not been established. ${ }^{10}$ The recent American Geriatrics Society Guiding Principles on the Care of Older Adults with Multimorbidity, ${ }^{11}$ British Geriatrics Society Fit for Frailty, ${ }^{5}$ and Asia-Pacific Clinical Practice Guidelines for the Management of Frailty ${ }^{6}$ make recommendations in relation to reducing inappropriate medications in older people. However, comprehensive principles for medication management in frail older people are lacking.

To address this, a multidisciplinary consensus group convened during the Optimizing Geriatric Pharmacotherapy through Pharmacoepidemiology Network workshop in Berlin, Germany, in October 2018. The consensus group comprised 4 geriatricians and 6 pharmacists from Australia, Finland, France, Italy, and Sweden. Using a modified nominal group technique, participants worked in mixed discipline pairs to generate a list of key principles under the themes of clinical practice (Table 1), research, and education (Table 2). The principles were consolidated and prioritized through a facilitator-led discussion until consensus was reached. This report presents each principle and key literature related to each.

\section{Principles for Clinical Practice}

The following principles for medication management in clinical practice (Figure 1) are particularly relevant to settings where frailty is prevalent including long-term care. The principles are founded on frailty being routinely assessed using a valid and appropriate approach for the specific clinical practice setting.

\section{Perform Medication Reconciliation and Maintain an Up-to-Date Medication List}

Frail older people may have discrepancies in their medication lists, exacerbated by multiple prescribers, frequent transitions of care, and reduced capacity to recall medications. The World Health Organization has reported that up to $67 \%$ of patients' hospital medication histories contained at least 1 error, with a higher incidence among people aged 65 years and above. ${ }^{12}$ Medication discrepancies are also common at transitions from hospital to long-term care with $20 \%$ of residents experiencing medication errors within 24 hours of hospital discharge. ${ }^{13}$ Medication reconciliation is the process of systematically obtaining, verifying, and documenting an accurate medication list, then comparing it against medication orders at admission, transfer, or discharge to identify and resolve discrepancies. ${ }^{12}$ Frail older people are likely to benefit due to high rates of polypharmacy, complex regimens, and potential confusion with generic and brand names. The primary clinician should ensure that patients have a reconciled medication list. ${ }^{14}$ The process of medication reconciliation and ensuring an up-todate medication list involves engaging the wider healthcare team, caregivers, and health technologies. ${ }^{14}$ An up-to-date medication list can assist with therapeutic decision-making, especially during transitions of care, where there may be time constraints and limited resources.

\section{Assess and Plan Based on Individual's Capacity to Self-Manage Medications}

Frail older people commonly experience difficulties selfmanaging complex regimens leading to errors or adverse drug events (ADEs), particularly among those with limited dexterity or vision or cognitive impairment. ${ }^{15,16}$ Structured approaches to assess capacity to self-manage are rarely implemented in routine clinical practice. ${ }^{15}$ Healthcare professionals are well placed to assess and advise on medication management services available to assist frail older people. For example, dose administration aids (eg, multidose drug dispensing) can be beneficial. However, a minimum level of comprehension is required to orientate to the corresponding day and time to administer medications. ${ }^{16}$ Supplying medications in dose administration aids can disempower frail older people accustomed to self-administering from original packaging. ${ }^{16}$ Given that medication management capacity is often a prerequisite to continue living independently at home, ${ }^{17}$ home care and community-based care 
Table 1

Principles for Clinical Practice in the Medication Management of Frail Older People and Examples of Strategies

\begin{tabular}{|c|c|}
\hline Principles for Clinical Practice & Strategies \\
\hline Perform medication reconciliation and maintain an up-to-date medication list & $\begin{array}{l}\text { - Systematically obtain, verify, and document an accurate medication list } \\
\text { - Compare against admission, transfer, or discharge orders to resolve } \\
\text { discrepancies } \\
\text { - Update medication list after every change in regimen to maintain accuracy }\end{array}$ \\
\hline Assess and plan based on individual's capacity to self-manage medications & $\begin{array}{l}\text { - Use standardized assessment tools to assess capacity to self-manage } \\
\text { medications } \\
\text { - Prioritize services to facilitate self-management and support caregivers }\end{array}$ \\
\hline Ensure appropriate prescribing and deprescribing & $\begin{array}{l}\text { - Assess therapeutic intents, time to benefit, dose optimization, potential ADEs, } \\
\text { benefits and risks of treatments, and patient preferences } \\
\text { - Deprescribe any unnecessary or potentially inappropriate medications }\end{array}$ \\
\hline Simplify medication regimens when appropriate to reduce unnecessary burden & $\begin{array}{l}\text { - Simplify regimens by consolidating administration times, standardizing } \\
\text { administration routes, and using long-acting or combination products }\end{array}$ \\
\hline Be alert to the contribution of medications to geriatric syndromes & $\begin{array}{l}\text { - Perform differential diagnosis of symptoms and thoroughly investigate for } \\
\text { possible ADEs or missed drug interactions prior to diagnosis and prescribing }\end{array}$ \\
\hline Regularly review medication regimens to align with changing goals of care & $\begin{array}{l}\text { - Conduct comprehensive medication reviews after changes in living setting or } \\
\text { health status to ensure medications remain clinically appropriate }\end{array}$ \\
\hline $\begin{array}{l}\text { Facilitate multidisciplinary communication among patients, caregivers, and } \\
\text { healthcare teams }\end{array}$ & $\begin{array}{l}\text { - Communicate frailty status to patients, caregivers, and healthcare teams } \\
\text { - Work collectively toward achieving treatment goals via multidisciplinary care }\end{array}$ \\
\hline
\end{tabular}

services can further support frail older people with managing medication regimens. Involvement of the patient and formal or informal caregivers are important when tailoring these services to account for their preferences.

\section{Ensure Appropriate Prescribing and Deprescribing}

Disease-specific clinical practice guidelines (CPGs) are typically based on research conducted in robust adults. Prescribing recommendations are often extrapolated to frail older people despite an absence of evidence for benefits and harm in this population. ${ }^{18}$ Prescribing decisions in frail older people require distinct assessment of therapeutic intent, time to benefit, dose optimization, potential ADEs or interactions, risk-benefit trade-off of the nominated treatment, and patient preferences. ${ }^{19}$ Deprescribing refers to the process of withdrawing inappropriate or unnecessary medication, supervised by a healthcare professional after consideration of benefits, risks, and treatment goals to improve health outcomes. ${ }^{20}$ The majority of older people are willing to discontinue 1 or more of their medications if recommended by the prescriber. ${ }^{21}$ In the context of frailty, this may assist to maintain quality of life and minimize medication burden. Deprescribing forms part of the prescribing continuum whereby discontinuation of certain medications may overcome possible ADEs or interactions, ${ }^{19}$ while allowing other essential medications to be started. The Screening Tool of Older Persons Prescriptions in Frail adults with limited life expectancy (STOPPFrail) ${ }^{22}$ and Beers criteria ${ }^{23}$ assist clinicians with deprescribing in frail older people.

\section{Simplify Medication Regimens when Appropriate to Reduce Unnecessary Burden}

Complex regimens are common among frail older people., ${ }^{4,17}$ Number of medications, dose frequencies, and administration routes contribute to regimen complexity. ${ }^{17}$ Frail older people with limited dexterity may find it challenging to administer inhalers, eye drops, open child-resistant containers, and halve tablets. ${ }^{17}$ Medications with

Table 2

Principles for Research and Education in the Medication Management of Frail Older People and Examples of Strategies

\begin{tabular}{|c|c|}
\hline Principles & Strategies \\
\hline \multicolumn{2}{|l|}{ Research } \\
\hline Include frail older people in RCTs & $\begin{array}{l}\text { - Understand the barriers to recruitment and retention of frail older people in } \\
\text { RCTs } \\
\text { - Develop strategies to improve and maintain participation }\end{array}$ \\
\hline Consider frailty status as an effect modifier & $\begin{array}{l}\text { - Conduct subanalyses on the impact of frailty status on study outcomes to } \\
\text { assess the potential modifying effects of frailty }\end{array}$ \\
\hline Ensure collection and reporting of outcome measures important in frailty & $\begin{array}{l}\text { - Use outcome measures that are prioritized by frail older people that } \\
\text { encompass both physical health and social well-being }\end{array}$ \\
\hline Assess impact of frailty on PK/PD & $\begin{array}{l}\text { - Conduct PK/PD studies in frailty including post-marketing population studies } \\
\text { - Develop animal models for frailty to facilitate better PK/PD understanding }\end{array}$ \\
\hline Encourage frailty research in under-researched settings & $\begin{array}{l}\text { - Encourage and conduct more frailty research in long-term care in order to } \\
\text { generate evidence specific to this setting }\end{array}$ \\
\hline Utilize routinely collected linked health data & $\begin{array}{l}\text { - Employ linked health datasets in frailty studies to perform different analyses } \\
\text { - Utilize big data to produce high quality evidence of comparative effectiveness }\end{array}$ \\
\hline \multicolumn{2}{|r|}{ 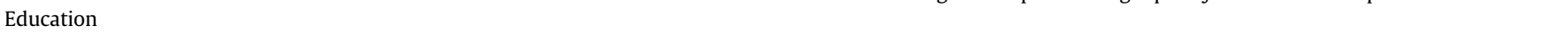 } \\
\hline Provide undergraduate and postgraduate education on frailty & $\begin{array}{l}\text { - Provide education on the assessment, documentation and consideration of } \\
\text { frailty at the time that medications are prescribed, dispensed and } \\
\text { administered }\end{array}$ \\
\hline Minimize low-value care related to medication management & $\begin{array}{l}\text { - Educate healthcare professionals on issues surrounding low-value care } \\
\text { - Support patient-centered care in reducing unnecessary medication use }\end{array}$ \\
\hline Improve health and medication literacy & $\begin{array}{l}\text { - Educate frail older people on the fundamental aspects of medication-taking to } \\
\text { ensure safe use of medications }\end{array}$ \\
\hline Incorporate evidence in relation to frailty into CPGs & $\begin{array}{l}\text { - Encourage guideline authors to consider the possible impact of frailty status } \\
\text { on prescribing recommendations }\end{array}$ \\
\hline
\end{tabular}




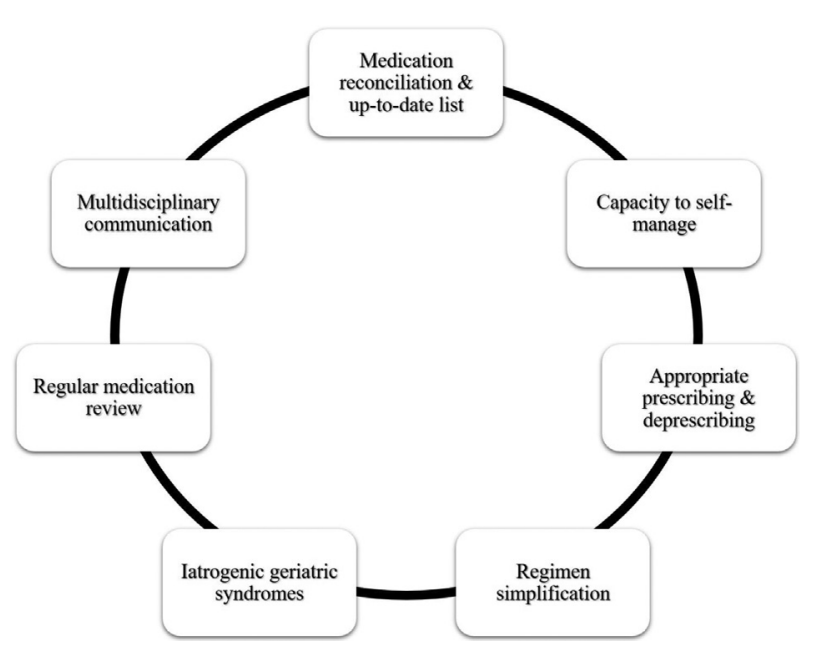

Fig. 1. Principles for clinical practice in the medication management of frail older people.

multiple daily dosing also contribute to higher pill burden, the extent of which may not be evident at the point of prescribing. Regimen complexity has been identified as a predictor of hospital discharge to nonhome settings. ${ }^{17}$ Regimen simplification without modification of therapeutic intent can often be achieved by consolidating administration times, standardizing administration routes, and switching to long-acting or combination products. ${ }^{24}$ Regimen simplification is a patient-centered process involving a multidisciplinary team approach that can be undertaken by clinicians who are familiar with medication products and formulations. A recent cluster-randomized controlled trial (RCT) of structured pharmacist-led regimen simplification in the long-term care setting found two-thirds of residents could have their regimens simplified. ${ }^{24}$

\section{Be Alert to the Contribution of Medications to Geriatric Syndromes}

Medications are a potential reversible cause of geriatric syndromes, including falls, incontinence, and cognitive impairment. ${ }^{25} \mathrm{Up}$ to $39 \%$ of delirium in older people is due to medications such as analgesics, benzodiazepines, anticholinergics, and antidepressants. ${ }^{26}$ Older people with geriatric syndromes also have higher odds of receiving potentially inappropriate medications. ${ }^{27}$ Vigilance is needed to identify potential prescribing cascades, whereby an ADE is misinterpreted as a new diagnosis and successive medications are prescribed to counter it. ${ }^{25}$ Clinicians have a role in identifying geriatric syndromes, and new signs or symptoms should be investigated as possibly medication-related prior to establishing new diagnosis and prescribing.

\section{Regularly Review Medication Regimens to Align with Changing Goals of Care}

Recent position statements highlight the importance of regular and comprehensive medication reviews for frail older people.,6,11 Frail older people may require more regular medication reviews and after changes in living setting to allow better adaptation of regimens to evolving health status and shift in treatment goals. ${ }^{5}$ Medication appropriateness should be considered in the context of a person's frailty status and projected life expectancy. Frail older people with advanced illness warrant reevaluation of the continual need of each medication. ${ }^{11}$ Medication reviews can be performed by healthcare professionals with the relevant background and expertise in medication management and geriatric care such as geriatricians, general practitioners ${ }^{5}$ or clinical pharmacists. $^{28}$

Facilitate Multidisciplinary Communication Among Patients, Caregivers, and Healthcare Teams

Fragmentation of care exists in the management of multimorbidity for older people. ${ }^{29}$ A person's frailty status should be communicated to those involved in medication prescribing, dispensing, and administration. Multidisciplinary communication improves coordination of care and supports the process of shared decision-making by encouraging all members of the healthcare team to work collectively toward achieving individual treatment goals. ${ }^{30,31}$ Advances in digital health will assist in streamlining transfer of clinical information. Active involvement of older people and/or their caregivers is also important to elucidate changing needs and preferences. ${ }^{30}$ Caregivers are typically familiar with daily medication management challenges encountered by the frail older person. In line with the patientcentered care approach, accounting for frail older people's expectations and priorities further facilitates engagement and empowerment across the continuum of care. ${ }^{30}$

\section{Principles for Research}

\section{Include Frail Older People in RCTs}

Frail older people are commonly excluded from RCTs due to cognitive impairment, multimorbidity, and polypharmacy ${ }^{18,32}$ RCT results may not be generalizable to frail older people. ${ }^{4,32}$ Frailty should be characterized at baseline and follow-up. ${ }^{33}$ Understanding whether there are changes in frailty status over time may be important, particularly interventions that may have an indirect impact on frailty status. Understanding the barriers to recruitment and retention of frail older people in RCTs allows development of strategies to improve and maintain participation, ${ }^{34}$ for example, establishing a partnership with staff that participants trust and being flexible with the place of study. ${ }^{34}$ Evaluation of the cost-effectiveness of RCTs is equally important, particularly in the frail population who are at risk of receiving less clinical benefits from a potentially costly intervention.

\section{Consider Frailty Status as An Effect Modifier}

Frailty status has been hypothesized to better predict medication response than chronological age. ${ }^{18}$ Frailty could act as an effect modifier to alter the risk-benefit ratio of preventive treatments in chronic diseases. ${ }^{4,25}$ Conducting subanalyses for frail older people is important to address evidence gaps. A recent observational study reported multiple antihypertensive use was associated with an increased risk of death in the frailest long-term care residents only. ${ }^{35}$ In contrast, a subanalysis of the Hypertension in the Very Elderly Trial Study suggested that frailty was not an effect modifier for the benefits of antihypertensive treatment in people aged 80 years and older. ${ }^{36}$ Further research is needed to determine whether specific frailty diagnosis or screening tools are more effective than others for predicting susceptibility to ADEs.

\section{Ensure Collection and Reporting of Outcome Measures Important in Frailty}

The multidimensional nature of geriatric care is consistent with the use of patient-centered clinical outcomes prioritized by frail older people and their caregivers. ${ }^{6}$ Clinical endpoints such as physical or cognitive function, quality of life, functional independence, and remaining at home encompass both physical health and social well- 
being of older people living with frailty. ${ }^{6,37}$ The Older Persons and Informal Caregivers Survey Composite Endpoint is a patient-reported outcome instrument developed to evaluate geriatric care by measuring health-related quality of life. ${ }^{37}$ In contrast, generic health status scales may contain items irrelevant to frail older people. Preference-weighted endpoints may incorporate outcome domains specific to frailty. ${ }^{37}$ Efforts to standardize outcome measures will support better delivery of geriatric care. There has also been a move to include frailty itself as an outcome in clinical trials. ${ }^{33}$

Assess Impact of Frailty on Pharmacokinetics and Pharmacodynamics

The lack of pharmacokinetics and pharmacodynamics (PK/PD) studies in frail older people presents challenges to the interpretation of medication safety and efficacy data. ${ }^{32,38}$ Despite limited studies evaluating PK/PD for medications used in frail older people, it is reported that potential changes in PK/PD may contribute to their vulnerability to ADEs. ${ }^{32,39}$ Sarcopenia may result in altered drug distribution of lipophilic medications including antipsychotics. ${ }^{25,40}$ Agerelated reductions in hepatic and renal functions were found to be augmented in frailty, subsequently reducing medication clearance. $^{39,40}$ Recent PK/PD findings suggest that commencing antihypertensives at one-half or one-quarter of the standard dose may be safer for frail older people. ${ }^{40}$ There has been debate whether it should be mandatory to conduct PK/PD studies in frailty for medications predominantly used by older people. ${ }^{38}$ Postmarketing population PK/ PD studies using electronic health records ${ }^{41}$ and development of animal models for frailty ${ }^{42}$ have great potential to further facilitate understanding.

\section{Encourage Frailty Research in Under-Researched Settings}

The prevalence of frailty in long-term care is as high as $50 \%$ whereas approximately $40 \%$ are prefrail. ${ }^{43}$ Residents of long-term care are among the highest consumers of medications and almost one-half are exposed to potentially inappropriate medications. ${ }^{44}$ However, only $2 \%$ of geriatric research is performed in this setting. ${ }^{28}$ Given that findings of studies from other settings may not be generalizable to frail residents in long-term care, research specific to this setting is important to optimize medication management. The Predictive Value of Blood Pressure and Arterial Stiffness in Institutionalized Very Aged Population Study found that multiple antihypertensive use was associated with higher risk of mortality among frail older residents with low systolic blood pressure $(<130 \mathrm{~mm} \mathrm{Hg}) .{ }^{45}$ Rigorous RCTs are needed to generate more evidence specific to under-researched settings because current CPGs are primarily based on studies conducted in predominately robust community-dwelling older people. ${ }^{18,45}$

\section{Utilize Routinely Collected Linked Health Data}

Better utilization of routinely collected linked health data will assist to bridge the evidence gap for medication use and outcomes in frail older people. Capitalizing on the digitalization and integration of health datasets will complement evidence generated through RCTs. ${ }^{46}$ Although RCTs remain the gold standard for measuring medication efficacy, observational research using "big data" can produce high quality evidence of comparative effectiveness. ${ }^{46}$ For example, the Hospital Frailty Risk Score is an automated screening tool generated from routinely collected electronic data. ${ }^{47}$ Following the Services and Health for Elderly in Long-Term Care Study, ${ }^{48}$ which collected data on residents' characteristics across 57 multinational long-term care settings, numerous studies have subsequently investigated other aspects of residents living with frailty based on the extensive database produced. Employing linked health data in frailty studies provides unprecedented opportunities to further examine the safety and effectiveness of medications in this population.

\section{Principles for Education}

Provide Undergraduate and Postgraduate Education on Frailty

There are knowledge gaps on frailty prevention and management among healthcare professionals. ${ }^{49}$ The concept of frailty should be incorporated into undergraduate and postgraduate medication management education. The principles for clinical practice (Table 1) may assist to design education programs. Initiatives such as the Prescribing Safety Assessment, ${ }^{50}$ although not specific to frail older people, may be valuable for evaluating competency in aligning medication regimens to changing goals of care and identifying iatrogenic geriatric syndromes. Similarly, education about the assessment, documentation, and consideration of frailty at the time that medications are prescribed, dispensed, and administered, including at transitions of care, may be advantageous for the implementation of frailty-attuned care. Lastly, optimizing medication management in frail older people requires effective multidisciplinary collaboration and, therefore, training in teamwork is highly recommended.

\section{Minimize Low-Value Care Related to Medication Management}

Low-value care includes continuation of potentially futile medications associated with ADEs. ${ }^{51,52}$ Commission bias may exacerbate defensive prescribing, whereby clinicians may feel inclined to continue prescribing a preventive medication that no longer has evidence of benefit, without considering the cost and potential harm associated with irrational medication use. ${ }^{51}$ Overdiagnosis through unnecessary screening or blood tests, increasing test sensitivity, and lower treatment thresholds can lead to subsequent overtreatment of frail older people with medications that may cause more harms than benefits. ${ }^{53}$ Educating healthcare professionals to minimize low-value care may reduce possible ADEs associated with polypharmacy. ${ }^{52}$ The Choosing Wisely campaign seeks to reduce routine, unnecessary use of treatments and eliminate waste through open conversations regarding necessities of treatments or procedures. ${ }^{54,55}$ Choosing Wisely recommendations for long-term care may be useful in guiding care for frail older people. ${ }^{54,55}$ Influence of cognitive biases and the practice of defensive medication in fear of litigation need to be addressed for such campaigns to be successful. ${ }^{51,53}$

\section{Improve Health and Medication Literacy}

Frailty prevalence may be higher among those with lower health literacy. ${ }^{56}$ Good medication literacy is fundamental to safe and effective medication use. Many preventable ADEs are attributable to poor medication literacy in terms of reading medication labels, understanding dosing instructions, calculating or manipulating doses, managing complex regimens, medication adherence, and decisions in case of missed doses. ${ }^{57}$ These issues can be magnified in the context of frailty with the presence of cognitive impairment, limited dexterity, age-related hearing loss, and low vision. The World Health Organization has launched the 5 Moments for Medication Safety in effort to improve medication literacy and reduce medication-related harm by engaging and empowering patients. ${ }^{58}$

\section{Incorporate Evidence in Relation to Frailty into CPGs}

CPG authors should be encouraged to consider the possible impact of frailty status on prescribing recommendations, ${ }^{30}$ particularly for conditions that disproportionately affect older people. Similarly, efforts to adapt CPGs to account for multimorbidity are paramount, 
given that $70 \%$ of frail older people also present with multimorbidity. ${ }^{2}$ Indeed, evidence for the efficacy and effectiveness of medications in the frail population is scarce and consensus-based recommendations often represent the best available evidence. ${ }^{30}$ Nevertheless, existing evidence can be better used to inform treatment of older people with multimorbidity by delivering relevant recommendations in relation to synergies, cautions, and contraindications. ${ }^{59}$ Principles outlined in Table 1 should be incorporated into disease-specific CPGs where relevant. Given that research in frailty will continually emerge with time, it is important that CPGs are frequently updated to reflect current evidence-based practice in managing medications for frail older people. Such initiatives can enhance the recognition of frailty, deliver best available evidence for frailty management, and improve health outcomes and quality of life for frail older people. ${ }^{6}$

\section{Implications for Practice, Policy, and Research}

Consideration of frailty status is important for guiding medication management (Table 1). Increasing numbers of frail older people and recognition that frailty may confer heightened risk of ADEs highlight the importance of an individualized approach to medication management. There is a lack of frailty-specific prescribing recommendations to guide medication management in this vulnerable population. The 7 principles for clinical practice, 6 principles for research, and 4 principles for education highlight different considerations for optimizing medication management in frail older people. These principles can be used in conjunction with existing best practice guidelines to help achieve optimal health outcomes for frail older people. Implementation of the principles will require multidisciplinary collaboration between healthcare professionals, researchers, educators, organizational leaders, and policymakers.

\section{References}

1. World Health Organization (WHO). Ageing and health. Available at: https:/ www.who.int/news-room/fact-sheets/detail/ageing-and-health. Accessed October 10, 2019.

2. Vetrano DL, Palmer K, Marengoni A, et al. Frailty and multimorbidity: A systematic review and meta-analysis. J Gerontol A Biol Sci Med Sci 2019;74: 659-666.

3. Clegg A, Young J, Iliffe S, et al. Frailty in elderly people. Lancet 2013;381: $752-762$.

4. Onder G, Vetrano DL, Marengoni A, et al. Accounting for frailty when treating chronic diseases. Eur J Intern Med 2018;56:49-52.

5. Turner G, Clegg A, British Geriatrics S, et al. Best practice guidelines for the management of frailty: A British Geriatrics Society, Age UK and Royal College of General Practitioners report. Age Ageing 2014;43:744-747.

6. Dent E, Lien C, Lim WS, et al. The Asia-Pacific Clinical Practice Guidelines for the Management of Frailty. J Am Med Dir Assoc 2017;18:564-575.

7. Fried LP, Tangen CM, Walston J, et al. Frailty in older adults: Evidence for a phenotype. J Gerontol A Biol Sci Med Sci 2001;56:M146.

8. Mitnitski AB, Mogilner AJ, Rockwood K. Accumulation of deficits as a proxy measure of aging. Sci World J 2001;1:323-336.

9. Rodríguez-Laso Á, Mora MÁC, Sánchez IG, et al. State of the art report on the prevention and management of frailty. Available at: http://www.advantageja. eu/images/State-of-the-Art-ADVANTAGE-JA.pdf. Accessed April 21, 2020.

10. Palmer K, Villani ER, Vetrano DL, et al. Association of polypharmacy and hyperpolypharmacy with frailty states: A systematic review and meta-analysis. Eur Geriatr Med 2018;10:9-36.

11. Boyd C, Smith CD, Masoudi FA, et al. Decision making for older adults with multiple chronic conditions: Executive Summary for the American Geriatrics Society Guiding Principles on the Care of Older Adults with Multimorbidity. J Am Geriatr Soc 2019;67:665-673.

12. World Health Organization (WHO). The High 5s Project Standard Operating Protocol - Assuring Medication Accuracy at Transitions in Care: Medication Reconciliation. p. 1-36. Available at: https://www.who.int/patientsafety/ implementation/solutions/high5s/h5s-sop.pdf?ua=1. Accessed November 4, 2019.

13. Elliott RA, Tran T, Taylor SE, et al. Gaps in continuity of medication management during the transition from hospital to residential care: An observationa study (MedGap Study). Aust J Ageing 2012;31:247-254.

14. Rose AJ, Fischer SH, Paasche-Orlow MK. Beyond medication reconciliation: The Correct Medication List. JAMA 2017;317:2057-2058.
15. Elliott RA, Marriott JL. Standardised assessment of patients' capacity to manage medications: A systematic review of published instruments. BMC Geriatr 2009; $9: 27$.

16. Elliott RA. Appropriate use of dose administration aids. Aust Prescr 2014;37: 46-50.

17. Wimmer BC, Cross AJ, Jokanovic N, et al. Clinical outcomes associated with medication regimen complexity in older people: A systematic review. J Am Geriatr Soc 2017;65:747-753.

18. Tan ECK, Sluggett JK, Johnell K, et al. Research priorities for optimizing geriatric pharmacotherapy: An international consensus. J Am Med Dir Assoc 2018;19: 193-199.

19. Hilmer SN, Gnjidic D, Le Couteur DG. Thinking through the medication list appropriate prescribing and deprescribing in robust and frail older patients. Aust Fam Phys 2012:41:924-948.

20. Reeve E, Gnjidic D, Long J, Hilmer S. A systematic review of the emerging definition of 'deprescribing' with network analysis: Implications for future research and clinical practice. Br J Clin Pharmacol 2015:80:1254-1268.

21. Reeve E, Wolff JL, Skehan M, et al. Assessment of attitudes toward deprescribing in older Medicare beneficiaries in the United States. JAMA Intern Med 2018;178:1673-1680

22. Lavan AH, Gallagher P, Parsons C, O'Mahony D. STOPPFrail (Screening Tool of Older Persons Prescriptions in Frail adults with limited life expectancy): Consensus validation. Age Ageing 2017;46:600-607.

23. Fick DM, Semla TP, Steinman M, et al. American Geriatrics Society 2019 Updated AGS Beers Criteria for Potentially Inappropriate Medication Use in Older Adults. J Am Geriatr Soc 2019;67:674-694.

24. Sluggett JK, Chen EYH, Ilomäki J, et al. Reducing the burden of complex medication regimens: Simplification of Medications Prescribed to Long-Term Care Residents (SIMPLER) Cluster Randomized Controlled Trial. J Am Med Dir Assoc. In press. 2020.

25. Hilmer SN, Gnjidic D. Prescribing for frail older people. Aust Prescr 2017;40: $174-178$.

26. Catic A. Identification and management of in-hospital drug-induced delirium in older patients. Drugs Aging 2011;28:737-748.

27. Muhlack DC, Hoppe LK, Stock C, et al. The associations of geriatric syndromes and other patient characteristics with the current and future use of potentially inappropriate medications in a large cohort study. Eur J Clin Pharmacol 2018; 74:1633-1644.

28. Sluggett JK, Ilomaki J, Seaman KL, et al. Medication management policy, practice and research in Australian residential aged care: Current and future directions. Pharmacol Res 2017;116:20-28.

29. Mc Namara KP, Breken BD, Alzubaidi HT, et al. Health professional perspectives on the management of multimorbidity and polypharmacy for older patients in Australia. Age Ageing 2017;46:291-299.

30. Muth C, Blom JW, Smith SM, et al. Evidence supporting the best clinical management of patients with multimorbidity and polypharmacy: A systematic guideline review and expert consensus. J Intern Med 2019;285: $272-288$.

31. Gowing A, Dickinson C, Gorman T, et al. Patients' experiences of a multidisciplinary team-led community case management programme: A qualitative study. BMJ Open 2016;6:e012019.

32. Ruiter R, Burggraaf J, Rissmann R. Under-representation of elderly in clinical trials: An analysis of the initial approval documents in the Food and Drug Administration database. Br J Clin Pharmacol 2019;85:838-844.

33. de Vries NM, Staal JB, van Ravensberg CD, et al. Outcome instruments to measure frailty: A systematic review. Ageing Res Rev 2011;10:104-114.

34. Provencher V, Mortenson WB, Tanguay-Garneau L, et al. Challenges and strategies pertaining to recruitment and retention of frail elderly in research studies: A systematic review. Arch Gerontol Geriatr 2014;59:18-24.

35. Kerry M, Bell JS, Keen C, et al. Multiple antihypertensive use and risk of mortality in residents of aged care services: A prospective cohort study. Aging Clin Exp Res; 2019.

36. Warwick J, Falaschetti E, Rockwood K, et al. No evidence that frailty modifies the positive impact of antihypertensive treatment in very elderly people: An investigation of the impact of frailty upon treatment effect in the HYpertension in the Very Elderly Trial (HYVET) study, a double-blind, placebo-controlled study of antihypertensives in people with hypertension aged 80 and over. BMC Med 2015;13:78.

37. Hofman CS, Lutomski JE, Boter $\mathrm{H}$, et al. Examining the construct and knowngroup validity of a composite endpoint for The Older Persons and Informal Caregivers Survey Minimum Data Set (TOPICS-MDS); A large-scale data sharing initiative. PLoS One 2017;12:e0173081.

38. Mangoni AA, Jansen PA, Jackson SH. Under-representation of older adults in pharmacokinetic and pharmacodynamic studies: A solvable problem? Expert Rev Clin Pharmacol 2013;6:35-39.

39. Reeve E, Trenaman SC, Rockwood K, Hilmer SN. Pharmacokinetic and pharmacodynamic alterations in older people with dementia. Expert Opin Drug Metab Toxicol 2017;13:651-668.

40. Peeters LEJ, Kester MP, Feyz L, et al. Pharmacokinetic and pharmacodynamic considerations in the treatment of the elderly patient with hypertension. Expert Opin Drug Metab Toxicol 2019;15:287-297.

41. Choi L, Beck C, McNeer E, et al. Development of a System for postmarketing population pharmacokinetic and pharmacodynamic studies using real-world data from electronic health records. Clini Pharmacol Therapeut 2020;107: 934-943. 
42. Kane AE, Hilmer SN, Mach J, et al. Animal models of frailty: Current applications in clinical research. Clin Interv Aging 2016;11:1519-1529.

43. Kojima G. Prevalence of frailty in nursing homes: A systematic review and meta-analysis. J Am Med Dir Assoc 2015;16:940-945.

44. Morin L, Laroche ML, Texier G, Johnell K. Prevalence of potentially inappropriate medication use in older adults living in nursing homes: A systematic Review. J Am Med Dir Assoc 2016;17:862.e1-862.e9.

45. Benetos A, Labat C, Rossignol P, et al. Treatment with multiple blood pressure medications, achieved blood pressure, and mortality in older nursing home residents: The PARTAGE Study. JAMA Intern Med 2015;175:989-995.

46. Angus DC. Fusing randomized trials with big data: The key to self-learning health care systems? JAMA 2015;314:767-768.

47. Gilbert T, Neuburger J, Kraindler J, et al. Development and validation of a Hospital Frailty Risk Score focusing on older people in acute care settings using electronic hospital records: An observational study. Lancet 2018;391:1775-1782.

48. Onder G, Carpenter I, Finne-Soveri H, et al. Assessment of nursing home residents in Europe: The Services and Health for Elderly in Long TERm care (SHELTER) study. BMC Health Serv Res 2012;12:5.

49. Windhaber T, Koula ML, Ntzani E, et al. Educational strategies to train health care professionals across the education continuum on the process of frailty prevention and frailty management: A systematic review. Aging Clin Exp Res 2018;30:1409-1415.

50. World Health Organization (WHO). WHO Drug Information - The Prescribing Safety Assessment, 32; 2018. p. 194-198. Available at: https://www.who.int/
medicines/publications/druginformation/issues/WHO_DI 32-2_MedicinesUse. pdf? ua =1. Accessed September 10, 2019.

51. Scott IA, Soon J, Elshaug AG, Lindner R. Countering cognitive biases in minimising low value care. Med J Aust 2017;206:407-411.

52. Morin L, Vetrano DL, Rizzuto D, et al. Choosing Wisely? Measuring the Burden of Medications in Older Adults near the End of Life: Nationwide, Longitudinal Cohort Study. Am J Med 2017;130:927-936.e9.

53. Moynihan R, Doust J, Henry D. Preventing overdiagnosis: How to stop harming the healthy. BMJ 2012;344:e3502.

54. Vance J. AMDA-choosing wisely. J Am Med Dir Assoc 2013;14:639.

55. McCormick WC. Updated Choosing Wisely® list from AGS highlights tests, treatments to consider carefully when caring for older patients. Geriatr Nurs 2015;36:250-251.

56. Lee DR, Santo EC, Lo JC, et al. Understanding functional and social risk characteristics of frail older adults: A cross-sectional survey study. BMC Fam Pract 2018;19:170.

57. Pouliot A, Vaillancourt R, Stacey D, Suter P. Defining and identifying concepts of medication literacy: An international perspective. Res Social Adm Pharm 2018; 14:797-804.

58. World Health Organization (WHO). 5 Moments for Medication Safety. Available at: https://www.who.int/patientsafety/medication-safety/5moments/en/. Accessed January 21, 2020.

59. Guthrie B, Payne K, Alderson P, et al. Adapting clinical guidelines to take account of multimorbidity. BMJ 2012;345:e6341. 